\title{
Early resources lead to persistent benefits for bumble bee colony dynamics
}

\author{
Rosemary Malfi ${ }^{1}$, Elizabeth Crone $^{2}$, Maj Rundlöf ${ }^{3}$, and Neal Williams ${ }^{1}$ \\ ${ }^{1}$ University of California Davis \\ ${ }^{2}$ Tufts University \\ ${ }^{3}$ Lund University
}

June 2, 2020

\begin{abstract}
Conditions experienced early in development can affect the future performance of individuals and populations. Demographic theories predict persistent population impacts of past resources, but few studies have experimentally tested such carry-over effects across generations or cohorts. We used bumble bees to test whether resource timing had persistent effects on withincolony dynamics over sequential cohorts of workers. We simulated a resource pulse for field colonies either early or late in colony development and estimated colony growth rates during pulse- and non-pulse periods. During periods when resources were not supplemented, early-pulse colonies grew faster than late-pulse colonies; early-pulse colonies grew larger as a result. These results reveal persistent effects of past resources on current growth and support the importance of transient dynamics in natural ecological systems. Early-pulse colonies also produced more queen offspring, highlighting the critical nature of resource timing for population, as well as colony, dynamics of a key pollinator.
\end{abstract}

\section{Introduction}

As a first approximation, ecologists often relate performance of plants or animals to environmental conditions in that time and place. Nonetheless, many ecological studies have highlighted the importance of past environmental conditions for current performance of individuals and populations. Such carry-over effects, which range from inter-life stage to inter-generational impacts, are well documented in life history literature (Pechenik 2006; Harrison et al. 2011; O'Connoret al. 2014; Liz \& Ruiz-Herrera 2016). For example, the nutritional environment experienced in juvenile stages of development in animals can influence development times (Pechenik 2006) and aspects of adult fitness including body size (e.g. Pereboom et al. 2003) and fecundity (e.g. Lindström 1999). In such cases, changes in individual quality (vital rates) can have lasting demographic consequences. Carry-over effects can be an important component of long-term population cycles (Beckerman et al. 2002), as well as responses to environmental stochasticity (Sabo \& Post 2008) and recovery from extreme resource pulses or dearth (Gratton \& Denno 2003; Yang et al. 2008).

Effects of past conditions on future population dynamics have been particularly well studied in stagestructured populations (Ezardet al. 2010; Stott et al. 2011). In many populations, vital rates (such as individual growth, survival, and reproduction) depend on the size of individual plants or animals. If these rates are constant through time, the population reaches a stable size distribution, and grows (or declines) at a constant rate associated with that size distribution. In fluctuating environments, the population growth rate in a particular year depends approximately equally on the vital rates individuals experience in that year, and the size distribution of individuals at the beginning of that year (Ellis \& Crone 2013; McDonald et al. 2016). In response to extreme changes in the environment, changes in size distribution can create persistent differences in abundance and transient multi-year changes in population growth rates, even after 
vital rates have returned to average levels (Gamelon et al. 2014). For example, a resource pulse might enable many individuals to grow faster during that pulse, leading to more large individuals and higher population growth rates for many years after the pulse is over. The increase in growth rate occurs simply because the population (after the pulse) started with more large individuals. Similarly, a resource dearth might reduce individual size, leading to a lack of large individuals and slower population growth rates after resources return. In structured population projection models, "transient dynamics" refer to the period between when a population's size distribution is perturbed, and when it returns to the size distribution determined by the current environmental conditions. During the past two decades, a large body of literature has focused on how to quantify transient dynamics using simulation models (starting with Neubert \& Caswell 1997; see reviews by (Ezard et al. 2010; Stottet al. 2011). However, few studies have tested these predictions with experiments (see Tenhumberg et al. 2009 for a notable exception).

We use bumble bees (Bombus vosnesnesnkii ) as a model system for understanding how current and historical environmental conditions affect population dynamics. Within-colony dynamics of bumble bees are useful for exploring population dynamics for several reasons. Bumble bees are annual eusocial insects with colonies that grow via the production of successive overlapping cohorts (generations) of worker bees. Colonies typically grow exponentially, often producing 5-10 (or more) worker cohorts during its development. After this growth phase, the colony stops making new workers and switches to reproduction (i.e. production of males and new queens, (Duchateau \& Velthuis 1988; Müller \& Schmid-Hempel 1992; Goulson 2010; Crone \& Williams 2016). Colonies persist for several months; however, individual foragers live 1-4 weeks (Rodd et al. 1980; Goldblatt \& Fell 2011; Malfi et al.2019) during which time they provide the resources to rear subsequent cohorts of workers (Alford 1975; Goulson 2010). Therefore, a single bumble bee colony can be considered as an exponentially growing population of workers, with the advantage that multi-cohort dynamics can be studied in nature in a single growing season.

Bumble bee colonies are also a tractable system for studying environmental drivers of population dynamics because it is straightforward to manipulate a known environmental driver of colony and population size: forage. Growth of bumble bee colonies is at least partly food-limited (Pelletier \& McNeil 2003). Larvae require pollen and nectar to develop into adults, and adult size is affected by the amount of food they receive as larvae (Couvillon \& Dornhaus 2009; Malfiet al. 2019). Adults require nectar to fuel various colony functions, including foraging itself. Colonies have a limited capacity to store food resources (Goulson 2010); as a result, the spatiotemporal availability of flowering plants strongly regulates colony growth and the size of the intra-season worker population (Westphal et al.2009; Rundlof et al. 2014; Crone \& Williams 2016; Kamperet al. 2016; Spiesman et al. 2017; Rundlof \& Lundin 2019). Therefore, it seems likely that short-term changes in forage resources would affect worker size distribution, leading to transient effects on population growth rate. Other carry-over effects (e.g., persistent effects on size-based survival or foraging ability of workers) are also possible (Malfi et al. 2019). In addition its feasibility as a model system, understanding the effects of forage resources on bumble bee colony growth and long-term population dynamics is of immediate practical importance. Bumble bees are important pollinators in natural and crop systems (Corbet et al. 1991; Thomson \& Goodell 2001; Kremen et al. 2002; Kleijn et al.2015), multiple bumble bee species are in decline (Bommarco et al. 2012; Colla et al. 2012; Kerr et al. 2015; Woodet al. 2019), and millions of dollars are invested annually in planting forage resources to support bumble bees and other bee populations (USDA Farm Services Agency 2019). Revealing the mechanistic connections between bumble bee colony and population dynamics and their resource environment is important for conservation efforts (Roulston \& Goodell 2011).

In this study, we experimentally varied the amount and timing of food available to free-foraging colonies of B. vosnesenskii and measured the effects on within-colony population dynamics. We supplemented colonies with abundant pollen and nectar resources for a limited duration (20 days), either earlier or later in the growth phase of colony development, simulating two resource environments that differed in their seasonal patterns of food availability. These supplementation treatments reflect the type of variation reported in realworld landscapes, with a resource "pulse" (e.g., natural resources or a mass-flowering crop) occurring either early or late in the season (Westphal et al. 2009; Williams et al. 2012; Rundlof et al. 2014). Thus, we refer 
to our supplementation and non-supplementation periods as "pulse" and "off-pulse" periods, respectively. Using this experimental design, we evaluated the impacts of varying resources levels and their timing on colony growth and reproduction, specifically: (1) whether colony growth rates during the pulse differed depending on pulse timing relative to colony development (early vs. late); (2) whether the growth rate during the off-pulse period (i.e. ambient resources only) depended on whether this period came before or after the pulse; (3) whether early-pulse and late-pulse colonies achieved similar peak sizes by the end of the colony growth phase; (4) whether the timing of the pulse affected the switch point from growth to decline and reproduction; and (5) whether early-pulse and late-pulse colonies differed in reproductive success.

\section{Material and Methods}

\section{Study Species and Site Selection}

The Yellow-Faced Bumble Bee (B. vosnesenskii ) is common along the west coast of North America, from British Columbia to Baja, California (Williams et al. 2014). We caught 99 wild, post-diapause B. vosnesenskii queens along roadsides in the vicinity of California State University Monterey Bay in California (N36 39 13.761, W121 48 6.109) during March 2017 (Permit \# SC-13698). These queens were transported to the lab at the University of California Davis where they were placed in rearing boxes under controlled conditions (see Williams et al.2012; Malfi et al. 2019). The 28 colonies that first generated more than 15 workers $(20.7+-$ 3.0, mean + - SD, range 17-25) were placed in the field between 6 and 9 weeks after queen capture. The first colonies were deployed on 18-April and the last colonies on 10-May (see Supporting Information, Appendix 1 for set-up details). On average, colonies weighed $25.2+-5.4 \mathrm{~g}$ (mean $+\mathrm{SD})$ at the time of placement.

We selected 14 sites in Colusa, Solano and Yolo Counties, California, USA (Fig 1) at which to deploy bumble bee colonies. Sites were selected based on proximity to riparian habitat, variation in proportion of seminatural and agricultural land in the surrounding landscapes, and geographical separation of at least $1 \mathrm{~km}$. The 1-km landscapes surrounding sites consisted of 2-63\% semi-natural habitat (oak savannah, riparian, oak woodland, forbs plantings), 37-91\% agricultural land (orchard, annual crops, pasture, vineyards) and $<1$ $25 \%$ other land uses (urban, water). Land use was identified through in-field inspection, complemented with satellite images (Google Maps 2017) for non-accessible areas, and analyzed in QGIS (QGIS Development Team, 2009) (for details, see Supporting Information, Appendix 2 ).

\section{Experimental Design and Field Methodology}

At each field site, we placed a pair of B. vosnesenskii colonies on a given date. Within the pair, we randomly assigned colonies to one of two food treatments: early supplementation (during the first 20 days in the field, early-pulse) or late supplementation (at 21-40 days in the field, late-pulse). In each treatment, food pulses were intended to represent elevated resources occurring earlier or later during the growth phase of colony dynamics (based on our past experience withB. vosnesenskii, cf. Crone \& Williams 2016; Kerr et al.2019; Malfi et al. 2019). Colony weight at field placement did not differ by experimental food treatment $\left(\mathrm{F}_{1,26}=\right.$ $2.04, P=0.17)$.

During pulses, a colony received (1) ad libitum access to artificial nectar (BioGluc(r), BioBest Canada Ltd.), which was delivered directly to the colony via a reservoir with an access point located inside of the colony box (Fig S1), and (2) pollen in the form fresh frozen honey bee pollen mixed with diluted artificial nectar at a 1:1 mass ratio, and encased in USDA certified organic beeswax (Koster-Keunan Inc., CT, USA), delivered to the colony on the first and $10^{\text {th }}$ day of the 20 -day pulse. The total weight of pollen provided to a colony was proportional to the colony weight at the time of each feeding in order to provide colonies $50 \%$ of their estimated needs for a 10-day interval (see Supporting Information, Appendix 3 ). We used this limit because superabundance of pollen in the nest can reduce foraging activity (Pelletier \& McNeil 2003). To determine whether and how foraging was affected by supplementation, we recorded the number of return trips per hour for both colonies during site visits throughout the experiment and analyzed this foraging activity information in relation to food treatment (seeSupporting Information, Appendix 4 ). At the end of the 20-day pulse, access to food supplements was terminated. 
We weighed colonies in the field every 10 days in order to track their growth across the season. We assumed that a colony's peak weight would be associated with its switch to reproduction (Crone \& Williams 2016) and pulled them from the field once they had declined in weight for two consecutive visits. This ensured that brood structure of the nest would be intact, allowing for final counting of reproductive output. Declining colonies are commonly invaded by insects and fungi that quickly destroy the nest structure. Upon removal from the field, colonies were frozen $(-20 \mathrm{o}$ C) until they could be dissected in the laboratory. Gyne production was determined by counting the number of queen brood cells present during dissections of the remnant brood structure. Queen cells can be reliably distinguished from worker/male cells based on their larger size (Williams et al. 2012). At the time of dissection, the majority of gynes had already eclosed; for the few colonies where some gynes were still in cocoons, both eclosed and uneclosed gynes were tabulated in the total gyne count.

\section{Analysis:}

\section{Model of colony growth}

We modelled within-colony dynamics as colony weight gain over time (see, e.g., (Westphal et al. 2009; Rundlof et al. 2015; Crone \& Williams 2016; Spiesman et al. 2017), which is much less invasive to measure than worker production over time (cf. Kerr et al.2019; Malfi et al. 2019). However, unlike most past studies, we analyzed weight gain using a change-point model in which the weight of each colony increases exponentially over the colony growth phase, then switches to decline during production of sexuals. The approach of fitting growth curves to each colony is more powerful than simply analyzing average weight through time because different colonies switch at different times, so information is lost by averaging (see Crone \& Williams 2016). In this case, we tested whether the colony growth rate depended on the resource status, leading to the following equation for colony dynamics:

$W_{t}=\{$

$$
\begin{array}{cc}
W_{0} \lambda_{p}{ }^{t_{p}} \lambda_{o}^{t_{o}} & \text { amp; if } t \leq \tau \\
W_{0} \lambda_{p}{ }^{t_{p}} \lambda_{o}^{t_{o}} \delta^{t-\tau} & \text { amp;if } t>\tau
\end{array} \quad \text { eq (1) }
$$

where $W_{t}$ is colony weight at time $t$ (measured in days); $W_{0}$ is the initial colony weight (estimated as a model parameter to account for observation error, e.g., changes in relative humidity and subsequent weight); $\lambda_{p}$ and $\lambda_{0}$ are the colony growth rates during resource supplementation (pulse) and the period of ambient resources (off-pulse), respectively; $t_{p}$ and $t_{0}$ are the amounts of time spend in supplemented and ambient conditions (respectively), up to time $t ; \delta$ is change in colony mass after decline starts $\left(\lambda_{0} \delta\right.$ is the rate of weight loss after the switch to decline, and $\tau$ is the time at which colonies switch from growth to decline. Assuming $\lambda_{0} \delta<1$ (i.e., the colony actually declines), then the colony reaches its peak mass at time $\tau$. We constrained eq (1) such that the pulse growth rate was not influenced once the decline started (post- $\tau$ ) (see Supporting Information, Appendix 5 and Appendix 6 ).

If carryover effects of resource conditions on subsequent growth are negligible, and colonies switch from growth to decline at the same time (regardless of treatment), then we would expect colony growth rates to be the same regardless of the order of treatments. In this case, colonies would reach the same mass at the end of the experiment; this is the familiar commutative property of multiplication. However, if colonies experience carry-over effects, then we might expect growth rates during the pulse and off-pulse periods to differ among treatments, and/or colonies to switch to reproduction at different times, leading to different peak weights.

1. Testing effects of resource pulse on colony growth parameters We used change-point regressions to estimate parameters for eq (1) for each colony (following Crone \& Williams 2016) (see Supporting information, Appendix 6 ), and then tested whether parameters differed among colonies in different treatments. Regressions were custom-coded in R (R Core Team 2018); a version of this code is available on GitHub for use by others (https://github.com/Aariq/bumbl). Visual inspection of fits for each colony are shown in Supporting Information (Fig S5,Appendix 5 ). We then tested for effects of the 
resource supplementation (early vs. late) on pulse $\left(\lambda_{p}\right)$ and off-pulse $\left(\lambda_{0}\right)$ growth rates, the timing of the switch point to reproduction $(\tau)$, and peak mass $\left(\lambda_{p}{ }^{t_{p}} \lambda_{o}{ }^{t_{o}}\right.$, evaluated at time $\left.\tau\right)$. Treatment effects were assessed with linear mixed models implemented using the lme4 package in $\mathrm{R}$ (Bates et al. 2015); within each model, colony was a replicate, and a random effect of site was included to account for non-independence of paired colonies placed at the same location. We analyzed switch points and log-transformed colony growth rates and peak mass using Gaussian family models.

2. Testing effects of resource pulse on queen production

We evaluated whether receiving a food resource pulse early or late in colony development influenced the count of queens produced by colonies using a negative binomial generalized linear mixed model (GLMM). Given the high number of colonies that did not produce gynes (19/28), we compared the fit of this model to one that also accounted for zero-inflation. Accounting for zero-inflation did not improve model fit, so we interpreted the results of the original negative binomial GLMM model. The GLMM was fit using the lme4 package (Bates et al. 2014), and the 0-inflated model was fit using the pscl package (Zeileis et al. 2008) in R.

\section{Results}

Within each food treatment, the growth rate of colonies during resource pulses $\left(\lambda_{p}\right)$ was higher than the growth rate off-pulse (ambient resources only, $\lambda_{0}$ ) (paired t-test of growth rate for each colony in pulse and ambient periods: $\mathrm{t}=10.77 \mathrm{df}=26, \mathrm{p}=<0.001$; Fig 2). Growth rates during pulses did not differ significantly between early-pulse and late-pulse treatments (Wald $\chi^{2}{ }_{1}=1.59 P=0.208$ ) (Fig 2); in both, colonies doubled in weight every $\sim 10$ days. However, early-pulse colonies grew at a significantly faster rate during the off-pulse period when compared to late-pulse colonies (Wald $\chi^{2}{ }_{1}=5.42, P=0.020$ ) (Fig 2). Late-pulse and early-pulse colonies switched from growth to decline after $\sim 40$ days in the field (Early: $\tau=$ 43.2 days $\left(\mathrm{CI}_{95 \%}[38.8,47.6]\right.$, Late: $\tau=42.8$ days $\left(\mathrm{CI}_{95 \%}[38.3,47.2]\right.$ ) (Wald $\left.\chi^{2}{ }_{1}=0.02, P=0.89\right)$. The faster growth rate, especially during the off pulse period led to significantly higher peak weights of early-pulse colonies $\left(W_{T}=158.4 \mathrm{~g} ; \mathrm{CI}_{95 \%}[108.7,231.2]\right)$ than of late-pulse colonies $\left(W_{T}=97.4 \mathrm{~g}\right.$; $\left.\mathrm{CI}_{95 \%}[66.8,142.1]\right)$ (Wald $\chi^{2}=4.55, P=0.033$ ) (Fig 3).

Half of early-pulse colonies (7/14) produced new queens, while only 2 of 14 late-pulse colonies did so. The number of new queens produced also was significantly greater for early-pulse colonies $\left(\bar{\Upsilon}=6.14, \mathrm{CI}_{95 \%}[2.23\right.$, 26.87]) than for late-pulse colonies $\left(\bar{\Upsilon}=0.21 ; \mathrm{CI}_{95 \%}[0.01,7.20]\right)$ (Wald $\left.\chi^{2}=30.38, \mathrm{P}<0.001\right)$.

\section{Discussion}

The timing of resource abundance relative to colony development profoundly impacted colony growth and reproduction of $B$. vosnesenskii . Colonies that received supplemental resources earlier in development achieved greater peak weights and also produced more queens - on average over 10 times more - than those colonies that received supplemental food later. Greater peak weights of early-pulse colonies were not driven by greater growth during a simulated resource pulse. Instead, early-pulse colonies had higher growth rates during the period that followed, in which they had access to ambient resources only. The increase in growth rate is consistent with expectations based on transient dynamics. Past studies have shown that higher food resources increase bumble bee body size (Sutcliffe \& Plowright 1988; Persson \& Smith 2011; Malfi et al. 2019), and that larger bumble bees bring back more resources (Goulson et al. 2002; Spaethe \& Weidenmüller 2002; Klein et al. 2017; Kerr et al. 2019) which would lead to higher colony growth rates after the pulse ended. Our early-pulse colonies had higher foraging rates compared to late-pulse colonies during their off-pulse periods, even when controlling for colony size, suggesting there was a more effective foraging workforce during the post-pulse period in early-pulse colonies (Fig S4). It is also possible that elevated resources may have led to additional carry-over effects beyond the change in body size structure per se. For example, Malfi et al. (2019) found that elevated resources increase bumble bee worker longevity, as well as body size. Conversely, captive workers deprived of pollen died earlier than those allowed to feed ad libitum on pollen (Smeets \& Duchateau 2003). Further investigation of these mechanisms would be an interesting avenue for future research. 
In contrast to persistent pulse effects in early-pulse colonies, we did not see a corresponding negative carryover effect of the off-pulse period in the late-pulse colonies, in that their growth rates were not different from those of early-pulse colonies during the pulse itself. One hypothesis for similar responses to the pulse is that early-pulse and late-pulse colonies had the same distribution of worker sizes at the start of the pulse; in other words, all colonies had similar body-size distributions when placed in the field regardless of treatment, and late-pulse colonies might have retained this distribution during the off-pulse period. Another possibility is that, because supplemental resources were added by hand to colonies, size-based foraging ability did not strongly affect resource gain during the period of supplementation; in other words, worker size distribution did not matter. Foraging levels were equally low during pulses for early-pulse and late-pulse colonies (Fig S4). By supplementing colonies at the nest, we also likely affected other aspects of colony dynamics, e.g., mortality associated with foraging (Rodd et al. 1980; Cresswell 2017; Malfi et al. 2018). A third hypothesis is that, during the pulse, colonies were limited by factors other than resource return. For certain Hymenoptera in particular, fecundity is sometimes limited by the rate of egg maturation (Zhang et al. 2014; Yadav \& Borges 2018), rather than resource return, particularly under high resource scenarios (Heimpel \& Rosenheim 1998; Neff 2008).

Despite the strong carryover effect of resource pulses on off-pulse growth rate, the timing of resource pulses did not significantly affect the switch point $(\tau)$. Optimality models of bumble bee colonies (Macevicz \& Oster 1976; Beekman et al. 1998) predict the timing of reproduction for bumble bee colonies should be earlier in high-resource environments. In these models, the key effect of resource abundance is on whether colonies are limited by queen egg production (presumably, high resource environments), which leads to earlier switches to reproduction, or limited by worker resource return (presumably, low resource environments), which leads to later switches to reproduction. Consistent with these models, Bowers (1986) observed that B. flavifrons colonies in high-resource meadows switched to reproduction sooner than those in low-resource meadows. It may be that bumble bee colonies respond differently to fluctuations in resource limitation (our experimental pulse treatments) than to chronically high or low resource conditions. It may also be that B. vosnesenskii life histories were resource limited (not egg limited) in both food resource treatments, and so timing of the switch from growth to reproduction was cued by end-of-season environmental conditions in both cases.

The availability of floral resources within landscapes varies throughout the season with pulses and dearth occurring at different times (Reader 1984; Liz \& Ruiz-Herrera 2016). In our study region, the Central Valley of California, there is a steady decline of flowers from the onset of the growing season to the dry season in natural areas, with mass-flowering crops producing late season resource pulses in some agriculturally dominated areas (Williams et al. 2012). In a European agricultural system, late season forage from massflowering clover increased queen abundance, but early season mass-flowering did not elevate queen numbers (Rundlöf et al. 2014) or colony-level queen production in similar landscapes (Westphal et al. 2009). It is tempting to speculate that persistent effects of the early-season pulse in our system reflected dynamics of ambient resources, specifically elevated late season resources in some landscapes. Indeed, new queen production was highest in four colonies that both received early supplements and encountered a natural increase in late-season ambient forage. However, analyses of growth rates across all colonies suggest that ambient resources are not the primary driving factor behind carry-over effects of the early-season pulse (Supporting Information, Appendix 2 ).

More generally, our work emphasizes the need to understand the temporal distribution of available flowering resources and its influence on population dynamics of bees. Pollinator conservation efforts are often based on planting floral resources to achieve greater abundance of forage resources but must also recognize the importance of resource continuity and timing (Schellhorn et al. 2015; Scheper et al. 2015; Williams et al. 2015). Our study strongly indicates the importance of resource timing for bumble bee colony and population health and supports targeted efforts to boost resources during the early season in areas where they are lacking, such as the agricultural lands in our study system (Williams et al. 2012). At its simplest, our study indicates that the timing of resources affects both the phenology of colony growth and the ultimate reproductive output, so season-long estimates of floral resources are not an adequate metric of habitat quality. 
In closing, our results emphasize the importance of the timing of resources for colony growth, reproduction, and phenology. Carry-over effects have been widely demonstrated in plant and animal populations, but only rarely linked to population dynamics (Beckerman et al.2002). For the particular case of transient dynamics, effects of changes in size structure have mostly been evaluated using models (McDonaldet al. 2016), not field experiments where populations are confronted both with large perturbations and ordinary environmental fluctuations. Numerous landscape studies of bees focus on the spatial context of land use and resource availability, whereas extremely few have investigated temporal dynamics within sites. Conservation planning for bumble bee populations will need to emphasize not only overall quality habitats but the temporal pattern of resources they contain. Our results also demonstrate the general importance of temporal variation for population dynamics, and the utility of bumble bee colony growth as a model system for understanding population dynamics in temporally varying environments.

\section{Acknowledgements}

We gratefully acknowledge funding from the National Science Foundation (DEB1354224 to E.C. and DEB1354022 to N.M.W.) and the Swedish Research Council (grant 330-2014-6439 to M.R.). We thank Katie Burns, Arvid Lindh, Clara Stuligross, John Mola, Jessica Drost, Charley Nye, Kimiora Ward, and Staci Cibotti for their assistance in the field and laboratory. We are also grateful to the landowners and managers of Yolo, Colusa and Solano counties who permitted us to use their properties as field sites.

\section{References}

Alford, D.V. (1975). Bumblebees . Davis-Poynter.

Bates, D., Mächler, M., Bolker, B. \& Walker, S. (2015). Fitting linear mixed-effects models using lme4. Journal of Statistical Software, 67, 1-48.

Beckerman, A., Benton, T.G., Ranta, E., Kaitala, V. \& Lundberg, P. (2002). Population dynamic consequences of delayed life-history effects. Trends in Ecology 83 Evolution , 17, 263-269.

Beekman, M., Lingeman, R., Kleijne, F.M. \& Sabelis, M.W. (1998). Optimal timing of the production of sexuals in bumblebee colonies.Entomologia Experimentalis et Applicata , 88, 147-154.

Bommarco, R., Lundin, O., Smith, H.G. \& Rundlöf, M. (2012). Drastic historic shifts in bumble-bee community composition in Sweden.Proceedings of the Royal Society B: Biological Sciences , 279, 309-315.

Bowers, M.A. (1986). Resource availability and timing of reproduction in bumble bee colonies (Hymenoptera: Apidae). Environ Entomol , 15, 750-755.

Colla, S.R., Gadallah, F., Richardson, L., Wagner, D. \& Gall, L. (2012). Assessing declines of North American bumble bees (Bombus spp.) using museum specimens. Biodivers Conserv , 21, 3585-3595.

Corbet, S.A., Williams, I.H. \& Osborne, J.L. (1991). Bees and the Pollination of Crops and Wild Flowers in the European Community.Bee World , 72, 47-59.

Couvillon, M.J. \& Dornhaus, A. (2009). Location, location, location: Larvae position inside the nest is correlated with adult body size in worker bumble-bees (Bombus impatiens). Philosophical Transactions Royal Society of London, B , 276, 2411-2418.

Cresswell, J.E. (2017). A demographic approach to evaluating the impact of stressors on bumble bee colonies. Ecological Entomology , 42, 221-229.

Crone, E.E. \& Williams, N.M. (2016). Bumble bee colony dynamics: quantifying the importance of land use and floral resources for colony growth and queen production. Ecology Letters , 19, 460-468.

Duchateau, M.J. \& Velthuis, H.H. (1988). Development and reproductive strategies in Bombus terrestris colonies. Behaviour , 107, 186-207. 
Ellis, M.M. \& Crone, E.E. (2013). The role of transient dynamics in stochastic population growth for nine perennial plants. Ecology , 94, 1681-1686.

Ezard, T.H.G., Bullock, J.M., Dalgleish, H.J., Millon, A., Pelletier, F., Ozgul, A., et al. (2010). Matrix models for a changeable world: the importance of transient dynamics in population management. Journal of Applied Ecology , 47, 515-523.

Gamelon, M., Gimenez, O., Baubet, E., Coulson, T., Tuljapurkar, S. \& Gaillard, J.-M. (2014). Influence of life-history tactics on transient dynamics: a comparative analysis across mammalian populations. The American Naturalist, 184, 673-683.

Goldblatt, J. \& Fell, R. (2011). Adult longevity of workers of the bumble bees Bombus fervidus (F.) and Bombus pennsylvanicus (De Geer) (Hymenoptera: Apidae). Canadian Journal of Zoology , 65, 2349-2353.

Goulson, D. (2010). Bumblebees: Behaviour, Ecology, and Conservation . Oxford University Press.

Goulson, D., Peat, J., Stout, J.C., Tucker, J., Darvill, B., Derwent, L.C., et al. (2002). Can alloethism in workers of the bumblebee, Bombus terrestris, be explained in terms of foraging efficiency? Animal Behaviour , 64, 123-130.

Gratton, C. \& Denno, R.F. (2003). Inter-year carryover effects of a nutrient pulse on Spartina plants, herbivores, and natural enemies.Ecology, 84, 2692-2707.

Harrison, X.A., Blount, J.D., Inger, R., Norris, D.R. \& Bearhop, S. (2011). Carry-over effects as drivers of fitness differences in animals. Journal of Animal Ecology , 80, 4-18.

Heimpel, G.E. \& Rosenheim, J.A. (1998). Egg Limitation in Parasitoids: A Review of the Evidence and a Case Study. Biological Control , 11, 160-168.

Kämper, W., Werner, P.K., Hilpert, A., Westphal, C., Blüthgen, N., Eltz, T., et al. (2016). How landscape, pollen intake and pollen quality affect colony growth in Bombus terrestris. Landscape Ecol, 31, 2245-2258.

Kerr, J.T., Pindar, A., Galpern, P., Packer, L., Potts, S.G., Roberts, S.M., et al. (2015). Climate change impacts on bumblebees converge across continents. Science, 349, 177-180.

Kerr, N.Z., Crone, E.E. \& Williams, N.M. (2019). Integrating vital rates explains optimal worker size for resource return by bumblebee workers. Functional Ecology , 33, 467-478.

Kleijn, D., Winfree, R., Bartomeus, I., Carvalheiro, L.G., Henry, M., Isaacs, R., et al. (2015). Delivery of crop pollination services is an insufficient argument for wild pollinator conservation.Nature Communications $, 6,1-9$.

Klein, S., Pasquaretta, C., Barron, A.B., Devaud, J.-M. \& Lihoreau, M. (2017). Inter-individual variability in the foraging behaviour of traplining bumblebees. Scientific reports , 7, 4561.

Kremen, C., Williams, N.M. \& Thorp, R.W. (2002). Crop pollination from native bees at risk from agricultural intensification. PNAS, 99, 16812-16816.

Lindström, J. (1999). Early development and fitness in birds and mammals. Trends in Ecology EJ Evolution , 14, 343-348.

Liz, E. \& Ruiz-Herrera, A. (2016). Potential impact of carry-over effects in the dynamics and management of seasonal populations.PLOS ONE, 11, e0155579.

Macevicz, S. \& Oster, G. (1976). Modeling social insect populations II: Optimal reproductive strategies in annual eusocial insect colonies. Behav Ecol Sociobiol , 1, 265-282.

Malfi, R.L., Crone, E. \& Williams, N. (2019). Demographic benefits of early season resources for bumble bee (B. vosnesenskii) colonies. Oecologia , 191, 377-388. 
Malfi, R.L., Walter, J.A., Roulston, T.H., Stuligross, C., McIntosh, S. \& Bauer, L. (2018). The influence of conopid flies on bumble bee colony productivity under different food resource conditions. Ecological Monographs , 88, 653-671.

McDonald, J.L., Stott, I., Townley, S. \& Hodgson, D.J. (2016). Transients drive the demographic dynamics of plant populations in variable environments. Journal of Ecology , 104, 306-314.

Müller, C.B. \& Schmid-Hempel, P. (1992). Correlates of reproductive success among field colonies of Bombus lucorum: the importance of growth and parasites. Ecological Entomology , 17, 343-353.

Neff, J.L. (2008). Components of nest provisioning behavior in solitary bees (Hymenoptera: Apoidea). Apidologie , 39, 30-45.

Neubert, M.G. \& Caswell, H. (1997). Alternatives to Resilience for Measuring the Responses of Ecological Systems to Perturbations. Ecology , 78, 653-665.

O'Connor, C.M., Norris, D.R., Crossin, G.T. \& Cooke, S.J. (2014). Biological carryover effects: linking common concepts and mechanisms in ecology and evolution. Ecosphere, 5, art28.

Pechenik, J.A. (2006). Larval experience and latent effects-metamorphosis is not a new beginning. Integr Comp Biol , 46, 323-333.

Pelletier, L. \& McNeil, J.N. (2003). The effect of food supplementation on reproductive success in bumblebee field colonies. Oikos, 103, 688-694.

Pereboom, J.J.M., Velthuis, H.H.W. \& Duchateau, M.J. (2003). The organisation of larval feeding in bumblebees (Hymenoptera, Apidae) and its significance to caste differentiation. Insectes soc., 50, 127-133.

Persson, A.S. \& Smith, H.G. (2011). Bumblebee colonies produce larger foragers in complex landscapes. Basic and Applied Ecology, S1439179111001265.

R Core Team. (2018). R: A language and environment for statistical computing. R Foundation for Statistical Computing, Vienna, Austria.

Reader, R.J. (1984). Comparison of the annual flowering schedules for Scottish heathland and mediterraneantype shrublands. Oikos, 1-8.

Rodd, F., Plowright, R. \& Owen, R. (1980). Mortality rates of adult bumble bee workers (Hymenoptera: Apidae). Canadian Journal of Zoology , 58, 1718-1721.

Roulston, T.H. \& Goodell, K. (2011). The role of resources and risks in regulating wild bee populations. Annu. Rev. Entomol. , 56, 293-312.

Rundlof, M., Andersson, G.K.S., Bommarco, R., Fries, I., Hederstrom, V., Herbertsson, L., et al. (2015). Seed coating with a neonicotinoid insecticide negatively affects wild bees. Nature, 521, 77-80.

Rundlof, M. \& Lundin, O. (2019). Can Costs of Pesticide Exposure for Bumblebees Be Balanced by Benefits from a Mass-Flowering Crop?Environ. Sci. Technol. , 53, 14144-14151.

Rundlof, M., Persson, A.S., Smith, H.G. \& Bommarco, R. (2014). Late-season mass-flowering red clover increases bumble bee queen and male densities. Biological Conservation , 172, 138-145.

Sabo, J.L. \& Post, D.M. (2008). Quantifying periodic, stochastic, and catastrophic environmental variation. Ecological Monographs, 78, 19-40.

Schellhorn, N.A., Gagic, V. \& Bommarco, R. (2015). Time will tell: resource continuity bolsters ecosystem services. Trends Ecol. Evol. (Amst.), 30, 524-530.

Scheper, J., Bommarco, R., Holzschuh, A., Potts, S.G., Riedinger, V., Roberts, S.P.M., et al. (2015). Local and landscape-level floral resources explain effects of wildflower strips on wild bees across four European countries. Journal of Applied Ecology, 52, 1165-1175. 
Smeets, P. \& Duchateau, M.J. (2003). Longevity of Bombus terrestris workers (Hymenoptera: Apidae) in relation to pollen availability, in the absence of foraging. Apidologie , 34, 333-337.

Spaethe, J. \& Weidenmuller, A. (2002). Size variation and foraging rate in bumblebees (Bombus terrestris). Insectes soc. , 49, 142-146.

Spiesman, B.J., Bennett, A., Isaacs, R. \& Gratton, C. (2017). Bumble bee colony growth and reproduction depend on local flower dominance and natural habitat area in the surrounding landscape. Biological Conservation, 206, 217-223.

Stott, I., Townley, S. \& Hodgson, D.J. (2011). A framework for studying transient dynamics of population projection matrix models. Ecology Letters , 14, 959-970.

Sutcliffe, G.H. \& Plowright, R.C. (1988). The effects of food supply on adult size in the bumble bee Bombus terricola Kirby (Hymenoptera: Apidae). The Canadian Entomologist , 120, 1051-1058.

Tenhumberg, B., Tyre, A.J. \& Rebarber, R. (2009). Model complexity affects transient population dynamics following a dispersal event: a case study with pea aphids. Ecology , 90, 1878-1890.

Thomson, J.D. \& Goodell, K. (2001). Pollen removal and deposition by honeybee and bumblebee visitors to apple and almond flowers. Journal of Applied Ecology , 38, 1032-1044.

USDA Farm Services Agency. (2019). Conservation Reserve Program Statistics .

Westphal, C., Steffan-Dewenter, I. \& Tscharntke, T. (2009). Mass flowering oilseed rape improves early colony growth but not sexual reproduction of bumblebees. Journal of Applied Ecology , 46, 187-193.

Whitehorn, P.R., O'Connor, S., Wackers, F.L. \& Goulson, D. (2012). Neonicotinoid Pesticide Reduces Bumble Bee Colony Growth and Queen Production. Science, 336, 351-352.

Williams, N.M., Regetz, J. \& Kremen, C. (2012). Landscape-scale resources promote colony growth but not reproductive performance of bumble bees. Ecology , 93, 1049-1058.

Williams, N.M., Ward, K.L., Pope, N., Isaacs, R., Wilson, J., May, E.A.,et al. (2015). Native wildflower plantings support wild bee abundance and diversity in agricultural landscapes across the United States. Ecol Appl , 25, 2119-2131.

Williams, P.H., Thorp, R.W., Richardson, L.L. \& Colla, S.R. (2014).Bumble Bees of North America . Princeton University Press.

Wood, T.J., Gibbs, J., Graham, K.K. \& Isaacs, R. (2019). Narrow pollen diets are associated with declining Midwestern bumble bee species.Ecology , 100, e02697.

Yadav, P. \& Borges, R.M. (2018). Why resource history matters: age and oviposition history affect oviposition behaviour in exploiters of a mutualism. Ecological entomology , 43, 473-482.

Yang, L.H., Bastow, J.L., Spence, K.O. \& Wright, A.N. (2008). What can we learn from resource pulses. Ecology , 89, 621-634.

Zeileis, A., Kleiber, C. \& Jackman, S. (2008). Regression models for count data in R. Journal of Statistical Software, 27, 1-25.

Zhang, Y., Zhang, H., Yang, N., Wang, J. \& Wan, F. (2014). Income resources and reproductive opportunities change life history traits and the egg/time limitation trade-off in a synovigenic parasitoid.Ecological entomology , 39, 723-731.

\section{Figure Legends}

Figure 1 Map of field sites where experimental colonies were placed (white dots, surrounded by black circles indicating the $1 \mathrm{~km}$ radius landscapes) in Colusa, Solano and Yolo counties in the northern Central Valley 
of California, USA (NW: N38 5818.02 N, 122deg02'44.90"W; SE: 38deg27'59.07”N, 121deg38'22.42"W). Imagery acquired though Google Earth v. 7.3.2.5776 (September 2017).

Figure 2 Mean +- 95\% CI of modeled rates of colony growth $(\lambda)$ during pulse and during off-pulse (ambient resource level) periods for early-pulse (black) and late-pulse (grey) colonies.

Figure 3 Mean modeled growth trajectories (bold lines) for early-pulse (black) and late-pulse (grey) colonies and modeled growth trajectories for individual colonies (thin lines). Vertical lines denote the 20-day intervals during which early-pulse and late-pulse colonies received supplemental food.

Figure 1

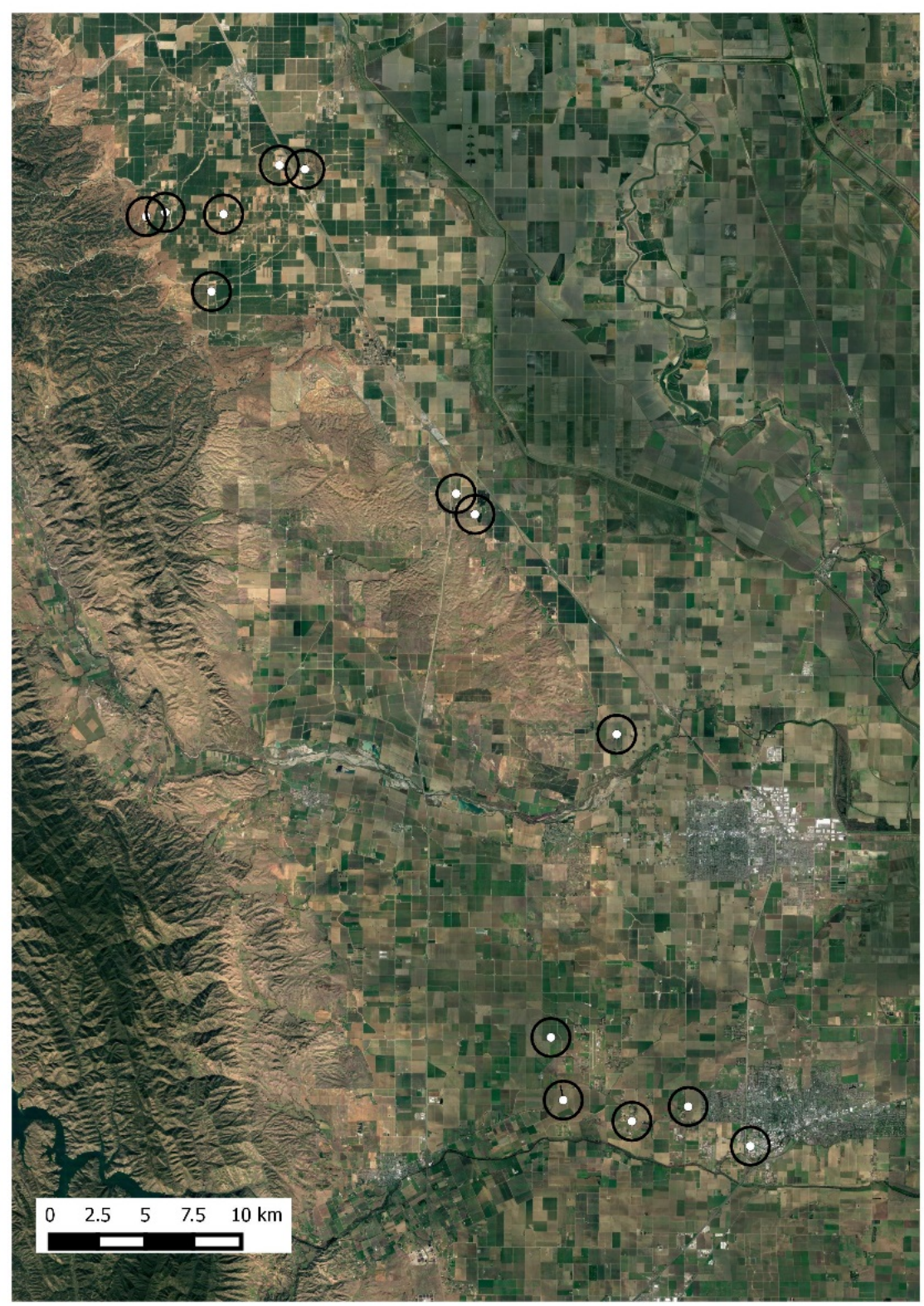

Figure 2 


\section{Hosted file}

image2.emf available at https://authorea.com/users/329014/articles/456152-early-resourceslead-to-persistent-benefits-for-bumble-bee-colony-dynamics

Figure 3

\section{Hosted file}

image3.emf available at https://authorea.com/users/329014/articles/456152-early-resourceslead-to-persistent-benefits-for-bumble-bee-colony-dynamics 